\title{
The Effect of Defective Early Phase Insulin Secretion on Postload Glucose Intolerance in Impaired Fasting Glucose
}

\author{
Mehmet SARGIN, Murat İKIIŞIK**, HALUK SARGIN, ASUmAn ORÇUN***, MüJgAn KAYA, \\ HüLYA GÖZÜ, REşAT DABAK*, OYA UYGUR BAYRAMIÇLI* AND ALI YAYLA** \\ Department of Endocrinology and Metabolism, Kartal Education and Research Hospital, Istanbul 34865, Turkey \\ *Department of Gastroenterology, Kartal Education and Research Hospital, Istanbul 34865, Turkey \\ **Department of Internal Medicine Clinic, Kartal Education and Research Hospital, Istanbul 34865, Turkey \\ ***Department of Biochemistry, Kartal Education and Research Hospital, Istanbul 34865, Turkey
}

\begin{abstract}
Impaired fasting glucose (IFG) and impaired glucose tolerance (IGT) are two risk groups for type 2 diabetes. Type 2 diabetes is characterized by both impaired insulin secretion and insulin resistance but their relative contribution to the development of hyperglycemia may differ due to heterogeneity of the disease. Combined glucose intolerance (CGI), on the other hand, seems to represent a more advanced stage of prediabetes that bears a distinctly higher risk of progression to diabetes and its comorbidities. This study has the aim to compare isolated IFG and CGI categories with respect to the degree of early phase insulin secretion abnormalities and insulin resistance. Subjects who had IFG (fasting glucose: $110-126 \mathrm{mg} / \mathrm{dl}$ ) were included in the study. A 75 -g oral glucose tolerance test (OGTT) with insulin response was done and subjects were classified according to the WHO criteria. Six subjects were excluded because they had diabetic glucose tolerance. A total of 66 patients $(53.4 \pm 11.1$ years, female/male: $48 / 18)$ were divided into two groups according to their glucose tolerance in OGGT (Group 1: isolated IFG and group 2: CGI). Early phase insulin secretion was measured by intravenous glucose tolerance test (IVGTT) and OGTT. Insulin resistance was assessed by the R value of the homeostasis model assessment (HOMA). We did not find any statistically significant difference between groups according to age, gender, body mass index (BMI), fasting glucose, fasting insulin, insulin-AUC (0-180 min) and HOMA$R$ values. In OGGT there was no statistically significant difference between $0^{\prime}, 30$ ', 60' and 90' insulin levels of the groups; only $120^{\prime}$ and $180^{\prime}$ insulin levels were higher in CGI than in IFG group $(\mathrm{p}<0.05)$. In IVGTT, there was no statistically significant difference between glucose levels of the groups. Furthermore, insulin response to intravenous glucose was higher in IFG than in CGI $(p<0.05)$. Our data demonstrate that isolated IFG and CGI are similar with respect to the degree of insulin resistance, and that subjects with CGI had a more prominent deficit in early phases of insulin secretion.
\end{abstract}

Key words: Impaired fasting glucose, Combined glucose intolerance, Early phase insulin secretion, Insulin resistance

(Endocrine Journal 52: 531-536, 2005)

TYPE 2 diabetes is characterized both by decreased insulin secretion and decreased insulin sensitivity, but the contribution of these factors to the etiology varies [1-3]. The relevance of insulin secretion abnormalities in the pathogenesis of type 2 diabetes mellitus has been extensively studied and a consensus has been reached. In order to fulfil its pivotal role in regulating glucose

Received: December 28, 2004

Accepted: June 6, 2005

Correspondence to: Mehmet SARGIN, M.D., Çakmak Mah. Soyak Yenişehir Palmiye Sitesi A-3 Blok D.20 Ümraniye, Istanbul, Turkey metabolism, insulin secretion must not only be quantitatively appropriate, but also possess qualitative, dynamic features that optimize insulin action on target tissues. In particular, increasing emphasis has been placed on the importance of the so-called first phase insulin secretion to glucose homeostasis [4].

Both impaired glucose tolerance (IGT) and impaired fasting glucose (IFG) represent intermediate metabolic states between normal and diabetic glucose homeostasis [5-8]. Furthermore, IGT is associated with an increase in cardiovascular-related mortality $[9,10]$. IFG is also a risk group for diabetes, but its relationship to atherosclerosis is less clear $[11,12]$. Combined glu- 
cose intolerance (CGI), combination of IFG and IGT, on the other hand, seems to represent a more advanced stage of prediabetes that bears a distinctly higher risk of progression to diabetes and other comorbid illnesses [13].

The aim of this study is to address the following questions in IFG and CGI groups; namely, first, what is the relation between the first phase insulin response to a brisk intravenous glucose challenge and the early insulin response following glucose ingestion; second, are IFG and CGI different in first phase insulin response and insulin resistance; and third, are they different in insulin response after a 75 -g oral glucose load?

\section{Research Design and Methods}

\section{Study group}

Subjects who had IFG (fasting glucose: 110-126 $\mathrm{mg} / \mathrm{dl}$ ) and were admitted to diabetes unit consecutively, were included in the study. In this study, ages of the subjects were between 40-65 years and had risk factors for type 2 diabetes. Subjects were excluded from the study if they had known diabetes or were taking any medication that affects glucose tolerance or for infections, liver or kidney disease, or thyroid function disorder. A 75-g oral glucose tolerance test (OGTT) was performed at baseline; subjects were classified into groups of glucose tolerance status according to the WHO 1999 diagnostic criteria. Six subjects were excluded because they had diabetic glucose tolerance. IFG was defined as having a fasting plasma glucose (FPG) level $\geq 110 \mathrm{mg} / \mathrm{dl}$ to $<126 \mathrm{mg} / \mathrm{dl}$ and a 2 -h postchallenge glucose level $<140 \mathrm{mg} / \mathrm{dl}$. Subjects with FPG levels $\geq 110 \mathrm{mg} / \mathrm{dl}$ to $<126 \mathrm{mg} / \mathrm{dl}$ and 2 -h during OGTT glucose level $\geq 140 \mathrm{mg} / \mathrm{dl}$ and $<200$ $\mathrm{mg} / \mathrm{dl}$ at 2 -h after glucose load were considered as exhibiting CGI. A total of 66 patients $(53.4 \pm 11.1$ years, female/male: 48/18) were divided into two groups according to their glucose tolerance in OGGT (group 1: isolated IFG and group 2: CGI).

\section{Anthropometric measurements}

Weight, height and body mass index (BMI) were measured under standardized conditions.

\section{Glucose tolerance}

After overnight fasting, the subjects received $75 \mathrm{~g}$ OGTT for the second time. Blood samples were collected before the test and every $30 \mathrm{~min}$ for a period of $3 \mathrm{~h}$. Both glucose and insulin levels were measured. All of the routine biochemical tests were carried out on Roche Diagnostics Modular Systems autoanalyser. Levels of insulin were measured by chemiluminometric immunoassay (DPC-Immulite 2000, cat. no.: 152).

\section{Intravenous glucose tolerance test}

Glucose $(0.5 \mathrm{~g} / \mathrm{kg}$ of body weight) was injected intravenously as a $20 \%$ solution within 1 to $3 \mathrm{~min}$ and blood was collected at $-10,-5,0,1,3,5$ and $10 \mathrm{~min}$ for both glucose and insulin levels.

\section{Statistical analysis}

Statistical analysis was performed with SPSS programme. A $p$ value less than 0.05 was considered statistically significant. Results are expressed as mean $\pm \mathrm{SD}$. Comparison between the two groups were made with Student's t-test and Chi square test.

\section{Results}

Clinical characteristics of the 66 study subjects according to their glucose tolerance status are shown in Table 1 . There was no statistically significant difference between isolated IFG and CGI groups according

Table 1. Characteristics of the study groups

\begin{tabular}{lccl}
\hline & IFG & IFG + IGT & \\
& n: 30 & n: 36 & p \\
\hline Age (years) & $54.6 \pm 13.5$ & $52.5 \pm 9.9$ & NS* \\
Gender (F/M**) & $22 / 8$ & $26 / 10$ & NS \\
BMI (kg/m $\left.{ }^{2}\right)$ & $31.7 \pm 5.5$ & $31.3 \pm 4.9$ & $\mathrm{NS}$ \\
Fasting Glucose (mg/dl) & $114.8 \pm 5.5$ & $117.4 \pm 8.5$ & $\mathrm{NS}$ \\
HbA1c (\%) & $5.5 \pm 0.3$ & $5.7 \pm 0.5$ & $\mathrm{NS}$ \\
Fasting insulin (IU/L) & $14.75 \pm 10.5$ & $13.09 \pm 6.6$ & $\mathrm{NS}$ \\
HOMA-R & $4.06 \pm 2.3$ & $3.49 \pm 1.4$ & $\mathrm{NS}$ \\
Insulin AUC $\chi$ & $11755.5 \pm 4325$ & $12784.5 \pm 642$ & $\mathrm{NS}$ \\
$\quad(0-180$ min) & & & \\
\hline
\end{tabular}

* NS: Non significant

** F/M: Female/Male

$\chi$ AUC: Area under the curve 
to age, gender, BMI, fasting glucose and fasting insulin. Insulin resistance as calculated by HOMA and insulin-area under curve (AUC, $0-180 \mathrm{~min}$ ) results were not a statistically significantly different between isolated IFG and CGI.

Blood glucose levels were significantly higher in CGI than in isolated IFG in OGTT at 60, 90, 120 and 180 minutes $(\mathrm{p}<.001)$. But at 0 and $30 \mathrm{~min}$, there was no statistically significant difference between groups according to the blood glucose levels (Fig. 1).

In OGGT there was no statistically significant difference between insulin levels of the groups at 0,60 and $90 \mathrm{~min}$. The $30 \mathrm{~min}$ insulin level was higher in IFG than CGI group $(77.2 \pm 19.5 \mathrm{U} / \mathrm{L}$ vs. $57.6 \pm 15.7 \mathrm{U} / \mathrm{L})$; however, the 120 and $180 \mathrm{~min}$ insulin levels were lower in IFG than in CGI group $(58.5 \pm 27.1 \mathrm{U} / \mathrm{L}$ vs. $87.5 \pm 25.7 \mathrm{U} / \mathrm{L}, \mathrm{p}<0.05 ; 20.6 \pm 11.9 \mathrm{U} / \mathrm{L}$ vs. $38.5 \pm$ $21.1 \mathrm{U} / \mathrm{L}, \mathrm{p}<0.05$, respectively) (Fig. 2).

In IVGTT, there was no statistically significant difference between glucose levels of the groups (Fig. 3). Furthermore, insulin response to intravenous glucose at 1, 3, 5 and 10 min were significantly higher in IFG than in CGI (Fig. 4).

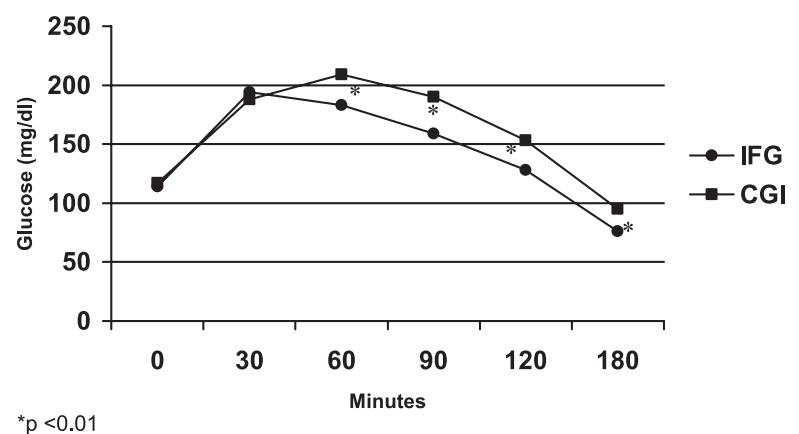

Fig. 1. Glucose levels of groups in OGTT

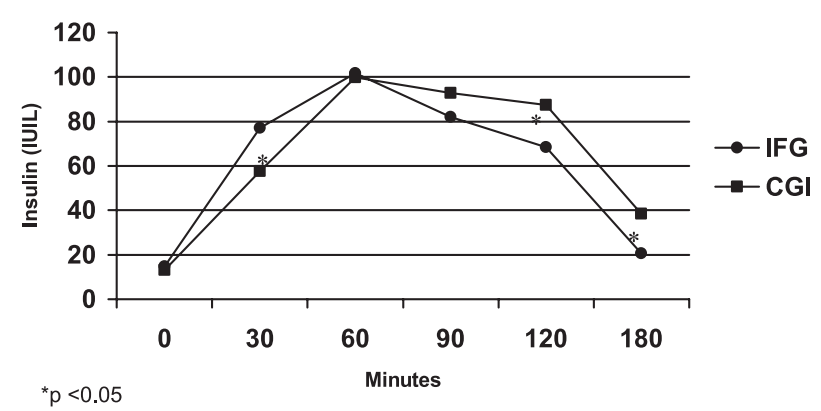

Fig. 2. Insulin levels of groups in OGTT

\section{Discussion}

Type 2 diabetes mellitus is a heterogeneous condition characterized by a dual pathogenic mechanism: insulin resistance and defective insulin secretion. Insulin resistance is believed to precede the development of type 2 diabetic patients. On the other hand, a loss of early-phase insulin response is common in type 2 diabetic patients and in people with IGT [12-16].

In order to assess insulin sensitivity, the euglycemic hyperinsulinemic clamp is the generally accepted method, but it is difficult to perform and time consuming; also its invasiveness and high cost have limited its use in clinical practice. Therefore we preferred to use HOMA, which is easy to perform and it has been shown that it is in correlation with the euglycemichyperinsulinemic clamp $(\mathrm{r}=0.88, \mathrm{p}<0.0001 ; \mathrm{r}=0.85$, $\mathrm{p}<0.0001$ and $\mathrm{r}=0.73, \mathrm{p}<0.0001)[17,18]$. A literature search using Medline found that the use of the HOMA model has been reported in 572 published works. In more than $50 \%$ of the reports, the model is used in nondiabetic populations [19]. However, several investigators have demonstrated that the insulin sensitivity can be predicted from measurements during

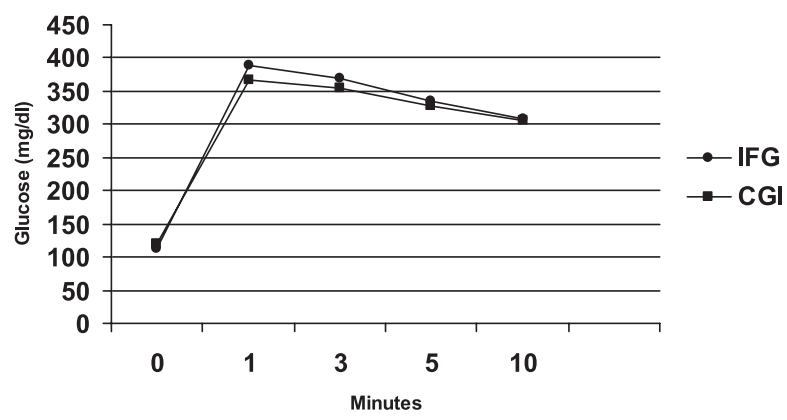

Fig. 3. Glucose levels of groups in IVGTT

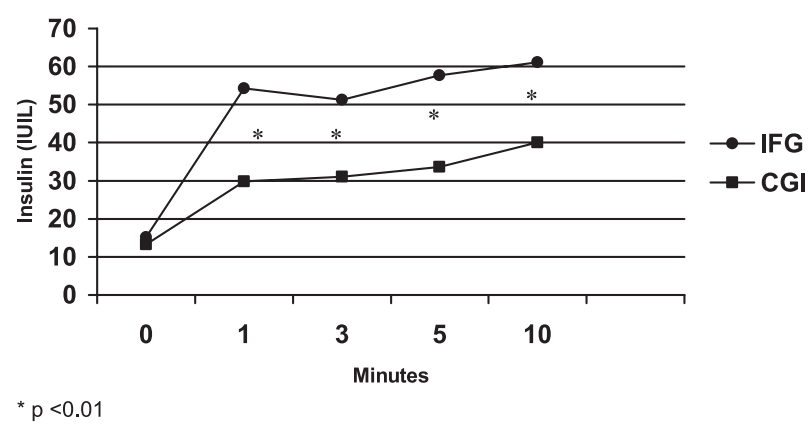

Fig. 4. Insulin levels of groups in IVGTT 
OGTT [20-23].

For determining the early phase insulin secretion of subjects, we used both IVGTT and OGTT. Although IVGTT still has tremendous research value in the evaluation of both the insulin secretory response to glucose and insulin sensitivity, it generally is not used for diagnostic purposes because the oral test is considered more physiologic. The insulin secretory response is greater after oral rather than parenteral glucose load. This effect is due to the activation of the entero-insular axis and the amplifying effect of gut incretins on insulin release [24].

In response to an i.v. glucose challenge, insulin secretion is characteristically biphasic. Within minutes of injection of glucose, insulin is rapidly secreted reaching an initial peak value in $5 \mathrm{~min}$. The early phase insulin release lasts no more than $10 \mathrm{~min}$ and is followed by a more sustained secretion lasting several hours, until the stimulus is removed or the plasma glucose concentration has returned to baseline values [14]. Therefore we collected blood samples within the first $10 \mathrm{~min}$ in IVGTT. On the other hand, $30 \mathrm{~min}$ plasma insulin concentration, one of the markers for early insulin secretion in OGTT, was used in the present study.

The Botnia Study suggests that insulin resistance as measured by HOMA is more increased in those with isolated IFG than in those with IGT. However, there was a significantly lower early insulin response in the IGT versus the IFG group [25]. Hanefeld et al. showed that isolated IFG and CGI had higher insulin resistance levels than IGT according to HOMA [13]. In a study by Davies et al., the fasting hyperglycemia group had a lower insulin secretion, whereas the IGT group had a higher 2-h insulin concentration [26].

Cross-sectional data from the RIAD study demonstrated that isolated IFG and isolated IGT are different with respect to the degree of insulin resistance and abnormalities in insulin secretion, and that subjects with IGT exhibit a deficit in the early and late phases of insulin secretion [13]. In the presence of weak earlyphase insulin secretion, plasma glucose will progressively rise causing sustained insulin release needed for the plasma glucose concentration to return towards baseline. In a group of 230 people with varying de- grees of glucose tolerance, 30-min-post OGTT plasma insulin concentration was inversely correlated to the 2-h plasma glucose concentration [22]. Fukushima et al. showed that in developing type 2 diabetes in Japanese patients, decreased basal and early insulin secretion had more pronounced contribution to glucose tolerance than the indices of insulin sensitivity [3]. Our results showed that there was no difference in insulin resistance between patients with isolated IFG and CGI. Although it is well documented that increases in insulin resistance exist long before diabetes is diagnosed, the differences of insulin resistance levels between the groups with various glucose intolerance status were contradictory in the literature $[8,13,25]$. However, our data showed that early phase insulin secretion was higher in isolated IFG than CGI in both OGTT and IVGTT. Results of our study for early phase insulin secretion were mostly compatible with the literature $[3,13]$. Hirose et al. have previously shown that a single dose nateglinide, an insulin secretagogue, almost normalises the glycemic response curve after a $75 \mathrm{~g}$ OGTT and restores impairment in early insulin response in IGT subjects despite the fact the area under the secreted insulin-time curve was not changed significantly [27]. In another study, Uchino et al. mentioned that the lack of rapid, pulsatile secretion of insulin in response to glycemic rise after oral glucose load, rather than insulin resistance, is responsible for postprandial glycemic response in obese type 2 diabetic patients [28].

On the other hand, $120 \mathrm{~min}$ insulin level was higher in CGI than isolated IFG in similarity with other studies $[8,13,26]$.

In the study by Torrens et al. it has been shown that ethnic differences influence the insulin sensitivity and beta-cell function in women without diabetes [29]. In this context our results reflect mainly the Turkish subjects and we have to take this into the consideration.

As a conclusion, our data from the study demonstrate that isolated IFG and CGI are similar with respect to the degree of insulin resistance, and that subjects with CGI had a more prominent deficit in early phases of insulin secretion in both OGTT and IVGTT. 


\section{References}

1. DeFronzo RA (1988) Lilly lecture 1987. The triumvirate: Beta-cell, muscle, liver. A collusion responsible for NIDDM. Diabetes 37: 667-687.

2. Porte D Jr (1991) Banting lecture 1990. Beta-cells in type II diabetes mellitus. Diabetes 40: 16-180.

3. Fukushima M, Usami M, Ikeda M, Nakai Y, Taniguchi A, Matsuura T, Suzuki H, Kurose T, Yamada Y, Seino $Y$ (2004) Insulin secretion and insulin sensitivity at different stages of glucose tolerance: A cross-sectional study of Japanese type 2 diabetes. Metabolism 53: 831835.

4. Caumo A, Livio L (2004) First-phase insulin secretion: does it exist in real life? Considerations on shape and function. Am J Physiol Endocrinol Metab 287: E371E385.

5. Alberti KGMM, Zimmet P (1988) Definition, diagnosis and classification of diabetes mellitus and its complications. 1. Diagnosis and classification of diabetes mellitus: provisional report of a WHO consultation. Diabet Med 15: 539-553.

6. Unwin N, Shaw J, Zimmet P, Alberti KGMM (2002) Impaired glucose tolerance and impaired fasting glycemia: the current status on definition and intervention. Diabet Med 19: 708-723.

7. Harris MI, Eastman RC, Cowie CC, Flegal KM, Eberhardt MS (1997) Comparison of diabetes diagnostic categories in the U.S. population according to the 1997 American Diabetes Association and World Health Organization diagnostic criteria. Diabetes Care 20: 1859-1862.

8. Festa A, D'Agostino R Jr, Hanley AJG, Karter AJ, Saad MF, Haffner SM (2004) Differences in insulin resistance in nondiabetic subjects with isolated impaired glucose tolerance or impaired fasting glucose. Diabetes 59: 1549-1555.

9. Fuller JH, Shipley MJ, Rose G, Jarrett RJ, Keen HC (1980) Coronary heart disease risk and impaired glucose tolerance: the Whitehall Study. Lancet 2: 13731376.

10. The DECODE study group (1999) Glucose tolerance and mortality: comparison of WHO and American Diabetes Association diagnostic criteria. Lancet 21: 617-621.

11. Tominaga M, Eguchi H, Manaka H, Igarashi H, Kato T, Sekikawa A (1999) Impaired glucose tolerance is a risk factor for cardiovascular disease, but not impaired fasting glucose: The Funagata Diabetes Study. Diabetes Care 22: 920-924.

12. Rodriguez BL, Curb JD, Burchfiel CM, Huang B, Sharp DS, Lu GY, Fujimoto W, Yano K (1996) Impaired glucose tolerance, diabetes and cardiovascular disease risk factor profiles: The Honolulu Heart Program. Diabetes Care 19: 587-590.
13. Hanefeld M, Koehler C, Fuecker K, Henkel E, Schaper F, Temelkova-Kurkeschiev T (2003) Insulin secretion and insulin sensitivity pattern is different in isolated impaired fasting glucose: the risk factor in Impaired Glucose Tolerance for Atherosclerosis and Diabetes study. Diabetes Care 26: 868-874.

14. Prato SD (2003) Loss of early insulin secretion leads to postprandial hyperglycemia. Diabetologia 46 (Suppl 1): M2-M8.

15. DeFronzo RA, Bonadonna RC, Ferannini E (1992) Pathogenesis of NIDDM. A balanced overview. Diabetes Care 15: 318-368.

16. Martin BC, Warram JH, Krolewski AS, Bergman RN, Soeldaner JS, Kahn CR (1992) Role of glucose and insulin resistance in development of type 2 diabetes mellitus: results of a 25 -year follow-up study. Lancet 340: 925-929.

17. Matthews DR, Hosker JP, Rudenski AS, Naylor BA, Treacher DF, Turner RC (1985) Homeostasis model assessment: insulin resistance and beta-cell function from fasting plasma glucose and insulin concentrations in man. Diabetologia 28: 412-419.

18. Bonora E, Targher G, Alberiche M, Bonadonna RC, Saggiani F, Ze MB, Monauni T, Muggeo M (2000) Homeostasis model assessment closely mirrors the glucose clamp technique in the assessment of insulin sensitivity: studies in subjects with various degrees of glucose tolerance and insulin sensitivity. Diabetes Care 23: 57-63.

19. Wallace TM, Levy JC, Matthews DR (2004) Use and abuse of HOMA modelling. Diabetes Care 27: 14871495.

20. Seltzer HS, Allen EW, Herron AL Jr, Brennan MT (1967) Insulin secretion in response to glycemic stimulus: Relation of delayed initial release to carbohydrate intolerance in mild diabetes mellitus. J Clin Invest 46: 323-335.

21. Mitrakou A, Kelley D, Mokan M, Veneman T, Pangburn T, Reilly J, Gerich J (1992) Role of reduced suppression of glucose production and diminished early insulin release in impaired glucose tolerance. $N$ Engl J Med 326: 22-29.

22. Del Prato S, Marchetti P, Bonadonna RC (2002) Phasic insulin release and metabolic regulation in type 2 diabetes. Diabetes (Suppl 1): S109-S116.

23. Taylor R, Magnusson I, Rothman DL, Cline GW, Caumo A, Cobelli C, Shulman GI (1996) Direct assessment of liver glycogen storage by $13 \mathrm{C}$ nuclear magnetic resonance spectroscopy and regulation of glucose haemostasis after a mixed meal in normal subjects. J Clin Invest 97: 126-132.

24. Eisenbarth GS (2001) Classification, diagnostic tests, and pathogenesis of type 1 diabetes mellitus. In: Becker 
KL (ed) Principles and Practice of Endocrinology and Metabolism. $3^{\text {rd }}$ edition, Lippincott Williams and Wilkins, Philadelphia, USA: 1308-1309.

25. Tripathy $\mathrm{D}$, Carlsson $\mathrm{M}$, Almgren $\mathrm{P}$, Isomaa $\mathrm{B}$, Taskinen MR, Tuomi T, Groop LC (2000) Insulin secretion and insulin sensitivity in relation to glucose tolerance: lessons from Botnia Study. Diabetes 49: 975-980.

26. Davies MJ, Raymond NT, Day JL, Hales C, Burden AC (2000) Impaired glucose tolerance and fasting hyperglycaemia have different characteristics. Diabet Med 17: 433-440.

27. Hirose T, Mýzuno R, Yoshimoto T (2002) The effects of nateglinide following oral glucose load in impaired glucose tolerance subjects: Rapid insulin stimulation by nateglinide in IGT subjects. Endocr J 49: 649-652.

28. Uchino H, Niwa M, Shimizu $T$, Nishiyama $K$, Kawamori R (2000) Impairment of early insulin response after glucose load, rather than insulin resistance, is responsible for postprandial hyperglycemia seen in obese type 2 diabetes: assessment using nateglinide, a new insulin secretagogue. Endocr J 47: 639-641.

29. Torrens JI, Skurnick J, Davidow AL, Korenman SG, Santoro N, Soto-Greene M, Lasser N, Weiss G (2004) Ethnic differences in insulin sensitivity and beta-cell function in premenopausal or early perimenopausal women without diabetes: the Study of Women's Health Across the Nation (SWAN). Diabetes Care 27: 354 361 . 